\title{
An immunoproteomic approach for characterization of dormancy within Staphylococcus epidermidis biofilms
}

\author{
Virginia Carvalhais $^{\mathrm{a}, \mathrm{b}}$, Frederico Cerveira ${ }^{\mathrm{c}}$, Manuel Vilanova ${ }^{\mathrm{d}, \mathrm{e}}$, Nuno Cerca $^{\mathrm{b}}$, \\ Rui Vitorino ${ }^{\mathrm{a}, \mathrm{f}, *}$ \\ a QOPNA, Mass Spectrometry Center, Department of Chemistry, University of Aveiro, 3810-193 Aveiro, Portugal \\ ${ }^{\mathrm{b}}$ CEB - Centre of Biological Engineering, LIBRO - Laboratory of Research in Biofilms Rosário Oliveira, University of Minho, Campus de Gualtar, \\ 4710-057 Braga, Portugal \\ ${ }^{c}$ Anatomia Patológica, Centro Hospitalar Baixo-Vouga, Avenida Artur Ravara, 3814-501 Aveiro, Portugal \\ d IBMC - Instituto de Biologia Molecular e Celular, Rua do Campo Alegre 83, Porto, Portugal \\ e ICBAS - Instituto de Ciências Biomédicas Abel Salazar, University of Porto, Rua de Rua de Jorge Viterbo Ferreira 228, 4050-313 Porto, Portugal \\ f iBiMED, Institute for Biomedical Research, University of Aveiro, Aveiro, Portugal
}

\section{A R T I C L E I N F O}

\section{Article history:}

Received 23 January 2015

Accepted 19 February 2015

\section{Keywords:}

S. epidermidis biofilm

Dormancy

Immunoproteomics

\begin{abstract}
A B S T R A C T
Virulence of Staphylococcus epidermidis is mainly attributed to surface colonization and biofilm formation in indwelling medical devices. Physiological heterogeneity of biofilms may influence host immune response and sensitivity to antibiotics. Dormant cells, among others, contribute to biofilm heterogeneity. The aim of this study was to identify immunogenic proteins of S. epidermidis biofilms associated with dormancy mechanism, by using two-dimensional electrophoresis (2-DE) immunoblotting and mass spectrometry (MS). A total of 19 bacterial proteins, recognized by human serum samples, were identified. These proteins were mainly involved in small molecule metabolic biological processes. Catalytic activity and ion binding were the most representative molecular functions. CodY and GpmA proteins were more reactive to sera when biofilm dormancy was induced, while FtnA and ClpP were more reactive when dormancy was prevented. This is the first work that identifies differences in immunoreactive proteins within bacterial biofilms with induced or prevented dormancy. Considering the importance of dormancy within biofilms, further evaluation of these proteins can provide insights into the mechanisms related to dormancy and help to improve current understanding on how dormancy affects the host immune response.
\end{abstract}

(c) 2015 Elsevier Ltd. All rights reserved.

\section{Introduction}

Staphylococcus epidermidis is an important opportunistic bacterium that does not produce highly aggressive virulence determinants (Otto, 2009). Its main virulence factor is the ability to form biofilms in indwelling medical devices (Otto, 2014). Biofilms are a community of surface-attached bacteria surrounded by an extracellular polymeric matrix composed of substances such as DNA, polysaccharides and proteins (Costerton et al., 1999). The clinical implications of bacterial growth in a biofilm mode are higher tolerance to antibiotics (Cerca et al., 2005) and tolerance to the innate immune response (Gray et al., 1984; Yao et al., 2005; Cerca et al., 2014; Cerca et al., 2006). S. epidermidis biofilm evasion of the host immune response may be caused by the production of several molecules that provide protection to host defenses, such

\footnotetext{
* Corresponding author. Tel.: +351234370695

E-mail address: rvitorino@ua.pt (R. Vitorino).
}

as proteins, exopolysaccharides and peptides with antimicrobial activity (Otto, 2012). Biofilm protection against components of the innate immune mechanisms (Vuong et al., 2004; Jesaitis et al., 2003; Leid et al., 2002), such as phagocytosis (Johnson et al., 1986) and activity of antimicrobial peptides (Kristian et al., 2008; Vuong et al., 2004), is mainly mediated by the extracellular polymeric matrix (Cerca et al., 2006). In S. epidermidis biofilms, polysaccharide intercellular adhesin (PIA), also named poly-N-acetylglucosamine (PNAG) is considered a major virulence factor in biomaterial associated infections (Rupp et al., 1999).

Nowadays, proteomic approaches are contributing to elucidate the immunological response to microorganisms (Fulton and Twine, 2013). Immunoproteomics allows the identification of immunogenic and immunoreactive proteins that may participate in host-pathogen interactions and in host immune response (Dennehy and McClean, 2012; Costa et al., 2013; Wang et al., 2013). Furthermore, immunoproteome analysis improves the understanding of pathogenesis and unravel novel therapeutics targets based on the repertoire of immunogens (Brady et al., 2006). 
Thus, plasma is one of the most relevant environmental factors in indwelling medical devices-related infections (Schuster et al., 2014). A few aspects of immune reaction to S. epidermidis infections were already elucidated (Sellman et al., 2005; Franca et al., 2014; Cheung et al., 2010; Hanke and Kielian, 2012; Scherr et al., 2014; Pourmand et al., 2006). By using serum from rabbits immunized with live $S$. epidermidis, or serum proteins eluted from the surface of bacteria grown in rabbit serum reactive against bacterial cell-surface extracts, immunogenic and serum binding proteins were identified by Western blotting (Sellman et al., 2005). Sellman and colleagues found 5 antigenic components candidates for the development of $S$. epidermidis vaccine, namely, acetyl-coenzyme A acetyltransferase (YqiL), $\mathrm{Na}^{+} / \mathrm{H}^{+}$antiporter (SE1873), lipoate ligase (SE0360), cysteine synthase (CysK), and alanine dehydrogenase (Ald). Also, Pourmand et al. identified autolysin AtlE, lipase (GehD) and surface protein ScaB antigenic components with therapeutic potential since they had opsonic activity in vitro (Pourmand et al., 2006).

Mature biofilms encompass cells with different metabolic activity (Rani et al., 2007), including dormant cells (Cerca et al., 2011). Dormancy is defined by a physiological state where bacteria persist without division for extended periods (Kaprelyants et al., 1993; Lewis, 2007). Moreover, dormant bacteria are associated with higher tolerance to antibiotics (Williamson et al., 2012; Kim et al., 2009; Shapiro et al., 2011; Cerca et al., 2014) and may determine the inflammatory profile of a biofilm (Cerca et al., 2011, 2014). Previously, we developed an in vitro model to modulate dormancy within S. epidermidis biofilms (Cerca et al., 2011). We were able to show that $S$. epidermidis biofilms with higher proportions of dormant bacteria induced a lower activation of murine macrophages, since it reduced in vitro pro-inflammatory cytokine production and lead to decreased expression of surface activation markers in vivo (Cerca et al., 2011). More recently, we performed a global transcriptome analysis where we found that translation was downregulated in dormant biofilms and, oxidation-reduction processes were associated with dormancy (Carvalhais et al., 2014). We also performed a quantitative proteomic analysis, where the ribosome synthesis pathway was associated with prevented dormancy, and ion binding and catalytic activity were found overexpressed in dormancy (Carvalhais et al., 2015).

To determine the immunoproteomic pattern of $S$. epidermidis biofilms with prevented and induced dormancy, we resolved whole cell lysate by 2-dimensional gel electrophoresis (2-DE) and performed immunoblotting with human sera. We then identified the immunoreactive protein spots by MALDI-TOF/TOF. With this work we intend to define the reactive protein repertoire of $S$. epidermidis biofilms with different proportions of dormant bacteria to human serum and contribute to decipher the host immune differences to dormancy.

\section{Materials and methods}

\subsection{Growth conditions}

Growth culture condition was performed as previously described (Cerca et al., 2011). S. epidermidis strain 9142 (isolated from blood culture (Mack et al., 1992)) was used to establish biofilms with higher and lower ratios of dormant cells. Briefly, one colony of $S$. epidermidis was inoculated in Tryptic Soy Broth (TSB) (LiofilChem, Roseto Degli Abruzzi, Italy) and incubated at $37^{\circ} \mathrm{C}$ in an orbital shaker at $120 \mathrm{rpm}$ for $18 \mathrm{~h}$. The overnight culture was adjusted to an optical density at $640 \mathrm{~nm}$ of $0.250( \pm 0.05)$ and $10 \mu \mathrm{L}$ of the suspension was transferred into a 24-well plate (Orange Scientific, Braine-l'Alleud, Belgium) containing $1 \mathrm{~mL}$ of TSB supplemented with $0.4 \%$ glucose $(\mathrm{v} / \mathrm{v}$ ) (TSB $0.4 \% \mathrm{G}$ ) (Fisher Scientific, Waltham, MA, USA) or TSB $0.4 \%$ G enriched with $20 \mathrm{mM}$ magnesium chloride $\left(\mathrm{MgCl}_{2}\right)$ (Merck, Darmstadt, Germany). The culture plates were then incubated at $37^{\circ} \mathrm{C}$ in an orbital shaker at $120 \mathrm{rpm}$ for $24 \mathrm{~h}$. After this period, the culture medium was removed and replaced by fresh TSB supplemented with $1 \%$ glucose $(\mathrm{v} / \mathrm{v})(1 \% \mathrm{G})$ or TSB $1 \% \mathrm{G}$ containing $20 \mathrm{mM} \mathrm{MgCl}_{2}\left(1 \% \mathrm{G}+\mathrm{Mg}^{2+}\right)$. Biofilms were then allowed to grow in the same conditions for an additional $24 \mathrm{~h}$. Next, biofilm culture medium was removed and biofilms were washed twice with phosphate buffered saline (PBS). Then, bacteria within the biofilms were resuspended in $1 \mathrm{~mL}$ of PBS. As previously described, biofilm dormancy was determined using the spread plate method in Trypticase Soy Agar (LiofilChem) through calculation of the number of $\mathrm{CFU} / \mathrm{mL}$ in each biofilm growth condition (Cerca et al., 2011). A reduction of about one log difference is typically expected in similarly grown biofilms without $\mathrm{Mg}^{2+}$ (Cerca et al., 2011).

\subsection{Preparation of protein extracts}

Total protein extraction was performed from multiple biofilm replicates, as previously described (Carvalhais et al., 2015). Briefly, biofilms were directly scrapped and resuspended with detergent extraction buffer, consisting of $25 \mathrm{mM}$ Tris- $\mathrm{HCl}(\mathrm{pH}=7.2)$ (Pharmacia Biotech, Uppsala, Sweden), $10 \mathrm{mM}$ CHAPS (Sigma-Aldrich, St. Louis, MO, USA), 0.5 M NaCl (VWR, Radnor, PA, USA), 5\% glycerol (Sigma-Aldrich) and $1 \mathrm{mM}$ PMSF (Sigma-Aldrich). Then, mechanical lysis was performed in a bead beating using glass beads of $0.1 \mathrm{~mm}$ (Sigma-Aldrich) in a FastPrep ${ }^{\circledR}$ cell disruptor (BIO 101, ThermoElectron Corporation) ( 3 cycles of $30 \mathrm{~s}$ and a speed of $6.5 \mathrm{~m} / \mathrm{s}$ ). After lysis, cell debris was removed by centrifugation $\left(15,000 \times \mathrm{g}\right.$ for $15 \mathrm{~min}$ at $\left.4{ }^{\circ} \mathrm{C}\right)$. Proteins were precipitated with $20 \%$ of trichloroacetic acid (TCA)-cold acetone. The lysates were mixed with 20\% TCA (Sigma-Aldrich) and incubated for $60 \mathrm{~min}$ at $-20^{\circ} \mathrm{C}$. Proteins were collected by centrifugation and washed three times with cold acetone. After drying, proteins were directly resuspended in 1\% CHAPS, $8 \mathrm{M}$ urea (Amersham Biosciences, Piscataway, NJ, USA), 2 M thiourea (Riedel-de Haën, Sigma-Aldrich) and 12 mM DTT (USB Corporation, Cleveland, OH, USA). Total protein was quantified using the RC-DC assay (Bio-Rad, Hercules, CA, USA), following the manufacturer's instructions.

\subsection{Two-dimensional electrophoresis (2-DE)}

A total of $80 \mu \mathrm{g}$ of protein was resuspended in rehydration sample buffer ( $8 \mathrm{M}$ urea, $2 \mathrm{M}$ thiourea, 1\% CHAPS, $12 \mathrm{mM}$ DTT, 0.5\% IPG buffer). Then, immobilized pH gradient (IPG) 3-10 non-linear strips, $7 \mathrm{~cm}$, (Immobiline ${ }^{\mathrm{TM}} \mathrm{pH}$ Gradient, GE Healthcare) were ingel rehydrated overnight for the first dimension isoelectric focusing (IEF), performed on a horizontal Ettan ${ }^{\mathrm{TM}}$ IPGPhor (Amersham Biosciences, USA). Isoelectric separation was performed using the following focusing program: $12 \mathrm{~h}$ at $50 \mathrm{~mW}$ (rehydration), $1 \mathrm{~h}$ at $150 \mathrm{~V}$ (gradient), $1 \mathrm{~h}$ at $500 \mathrm{~V}$ (gradient), $1 \mathrm{~h}$ at $1000 \mathrm{~V}$ (gradient) and $90 \mathrm{~min}$ at $5000 \mathrm{~V}$ ("step-and-hold"). After IEF, IPG strips were equilibrated with equilibration buffer (2\% (w/v) SDS, $6 \mathrm{M}$ urea, 30\% glycerol, $0.05 \mathrm{M}$ Tris- $\mathrm{HCl} \mathrm{pH} 8.8$ and $20 \mathrm{mg} / \mathrm{ml} \mathrm{DTT}$ ) for $30 \mathrm{~min}$ at room temperature. Strips were then placed on the top of a $12 \%$ SDS-PAGE gel for the second dimension separation and ran at a constant voltage. Gels were stained with colloidal Coomassie G-250 or gels were transferred onto a nitrocellulose membrane. Proteins were blotted on a nitrocellulose membrane (Whatman ${ }^{\circledR}$, Protan) in transfer buffer (25 mM Tris, $192 \mathrm{mM}$ glycine, pH 8.3 and 20\% methanol) during $2 \mathrm{~h}$ at $200 \mathrm{~mA}$. Stained gels were analyzed by using Melanie analysis software v.7.0 (GeneBio, Switzerland). Protein separations by 2-DE was carried out three independent times. The signal intensities of proteins spots were compared among both conditions and scored by fold-change. 
Table 1

\begin{tabular}{|c|c|c|c|c|c|c|c|c|c|}
\hline Spot & Protein & Accession number & Protein name & $M_{\mathrm{w}}(\mathrm{KDa})$ & $\mathrm{p} I$ & Function & PSORTb localization & Cello localization & Number of epitopes \\
\hline 1 & FtnA & Q5HN41 & Ferritin & 19.58 & 4.55 & Iron-storage protein & Cytoplasmic & Cytoplasmic & 7 \\
\hline 2 & ClpP & Q5HQW0 & $\begin{array}{l}\text { ATP-dependent Clp } \\
\text { protease proteolytic } \\
\text { subunit }\end{array}$ & 21.38 & 5 & $\begin{array}{l}\text { Cleaves peptides in various proteins in a } \\
\text { process that requires ATP hydrolysis. Has a } \\
\text { chymotrypsin-like activity. Plays a major role } \\
\text { in the degradation of misfolded proteins }\end{array}$ & Cytoplasmic & Cytoplasmic & 7 \\
\hline 3 & Pgk & Q5HQV3 & Phosphoglycerate kinase & 42.74 & 4.76 & $\begin{array}{l}\text { Catalyzes the transference of a phosphate } \\
\text { group from 3-phospho-D-glycerate to ADP }\end{array}$ & Cytoplasmic & Cytoplasmic & 14 \\
\hline 4 & SsaA & Q5HLV2 & $\begin{array}{l}\text { Staphylococcal secretory } \\
\text { antigen SsaA }\end{array}$ & 27.91 & 8.4 & $\begin{array}{l}\text { Not known; immunogenic protein expressed } \\
\text { during sepsis and particularly during episodes } \\
\text { of infective endocarditis }\end{array}$ & Extracellular & Extracellular & 16 \\
\hline 5 & EF-TU & Q5HRK4 & Elongation factor $\mathrm{Tu}$ & 43.16 & 4.7 & $\begin{array}{l}\text { This protein promotes the GTP-dependent } \\
\text { binding of aminoacyl-tRNA to the A-site of } \\
\text { ribosomes during protein biosynthesis }\end{array}$ & Cytoplasmic & Cytoplasmic & 22 \\
\hline 6 & Fda & Q5HL21 & $\begin{array}{l}\text { Fructose-bisphosphate } \\
\text { aldolase class } 1\end{array}$ & 32.99 & 4.89 & $\begin{array}{l}\text { Glycolytic enzyme that catalyses D-fructose } \\
\text { 1,6-bisphosphate into glycerone phosphate } \\
\text { and D-glyceraldehyde 3-phosphate }\end{array}$ & Unknown & Cytoplasmic & 8 \\
\hline 7 & TpiA & Q5HQV2 & Triosephosphate isomerase & 27.37 & 4.9 & $\begin{array}{l}\text { Catalyses the interconversion of } \\
\text { D-glyceraldehyde 3-phosphate and glycerone } \\
\text { phosphate }\end{array}$ & Cytoplasmic & Cytoplasmic & 13 \\
\hline 8 & GpmA & Q5HLIO & $\begin{array}{l}\text { 2,3-Bisphosphoglycerate- } \\
\text { dependent } \\
\text { phosphoglycerate mutase }\end{array}$ & 26.7 & 6.46 & $\begin{array}{l}\text { Catalyzes the interconversion of } \\
\text { 2-phosphoglycerate and 3-phosphoglycerate }\end{array}$ & Cytoplasmic & Cytoplasmic & 10 \\
\hline 9 & CodY & Q5HPT7 & $\begin{array}{l}\text { GTP-sensing } \\
\text { transcriptional pleiotropic } \\
\text { repressor CodY }\end{array}$ & 28.75 & 5.61 & $\begin{array}{l}\text { It is a GTP-binding protein that senses the } \\
\text { intracellular GTP concentration as an indicator } \\
\text { of nutritional limitations. At low GTP } \\
\text { concentration it no longer binds GTP and stop } \\
\text { to act as a transcriptional repressor }\end{array}$ & Cytoplasmic & Cytoplasmic & 15 \\
\hline 10 & Ldh & Q5HL31 & L-lactate dehydrogenase & 34.1 & 4.93 & Catalyzes the reduction of pyruvate into lactate & Cytoplasmic & Cytoplasmic & 9 \\
\hline 11 & GpmI & Q5HQV1 & $\begin{array}{l}\text { 2,3-Bisphosphoglycerate- } \\
\text { independent } \\
\text { phosphoglycerate mutase }\end{array}$ & 56.36 & 4.8 & $\begin{array}{l}\text { Catalyzes the interconversion of } \\
\text { 2-phosphoglycerate and 3-phosphoglycerate }\end{array}$ & Cytoplasmic & Cytoplasmic & 18 \\
\hline 12 & FusA & Q5HRK5 & Elongation factor $G$ & 76.88 & 4.8 & $\begin{array}{l}\text { This protein promotes the GTP-dependent } \\
\text { translocation of the nascent protein chain from } \\
\text { the A-site to the P-site of the ribosome }\end{array}$ & Cytoplasmic & Cytoplasmic & 34 \\
\hline 13 & DnaK & Q5HNW6 & Chaperone protein DnaK & 66.15 & 4.57 & Acts as a chaperone & Cytoplasmic & Cytoplasmic & 28 \\
\hline 14 & GroEL & Q5HMZ1 & $60 \mathrm{kDa}$ chaperonin & 57.75 & 4.59 & $\begin{array}{l}\text { Prevents misfolding and promotes the } \\
\text { refolding and proper assembly of unfolded } \\
\text { polypeptides generated under stress } \\
\text { conditions }\end{array}$ & Cytoplasmic & Cytoplasmic & 26 \\
\hline 15 & ButA & Q5HKG6 & $\begin{array}{l}\text { Diacetyl reductase } \\
\text { [(S)-acetoin forming] }\end{array}$ & 27.91 & 4.66 & $\begin{array}{l}\text { Catalyzes the irreversible reduction of } \\
\text { 2,3-butanediol to (S)-acetoin in the presence of } \\
\text { NADH }\end{array}$ & Cytoplasmic & Cytoplasmic & 12 \\
\hline 16 & PfkA & Q5HNK6 & 6-phosphofructokinase & 34.88 & 5.34 & $\begin{array}{l}\text { Catalyzes the reaction of D-fructose } \\
6 \text {-phosphate into D-fructose } 1,6 \text {-bisphosphate }\end{array}$ & Cytoplasmic & Cytoplasmic & 12 \\
\hline 17 & Asp23 & Q5HM47 & Alkaline shock protein 23 & 19 & 4.92 & May play a key role in alkaline $\mathrm{pH}$ tolerance & Unknown & Cytoplasmic & 7 \\
\hline 18 & Ald & Q5HNJ6 & Alanine dehydrogenase & 40.2 & 5.03 & $\begin{array}{l}\text { May play a role in cell wall synthesis as } \\
\text { L-alanine is an important constituent of the } \\
\text { peptidoglycan layer }\end{array}$ & Cytoplasmic & Cytoplasmic & 14 \\
\hline 19 & RpsA & Q5HP69 & $30 \mathrm{~S}$ ribosomal protein $\mathrm{S} 1$ & 43.37 & 4.46 & $\begin{array}{l}\text { Binds mRNA; thus facilitating recognition of } \\
\text { the initiation point. It is needed to translate } \\
\text { mRNA with a short Shine-Dalgarno (SD) } \\
\text { purine-rich sequence }\end{array}$ & Cytoplasmic & Cytoplasmic & 15 \\
\hline
\end{tabular}




\subsection{Immunoblotting}

Sera samples were obtained from three volunteers after informed consent was obtained. The experiment was approved by the Ethics Committee of Instituto Ciências Biomédicas Abel Salazar (document number 081/2014).

Nitrocellulose membranes were blocked in 5\% BSA (Sigma-Aldrich) in TBS-T (Tris-Buffered Saline-Tween 20) for $2 \mathrm{~h}$. Then, membranes were incubated with human serum $(1: 200)$ for $2 \mathrm{~h}$ at room temperature. Following this incubation, membranes were washed with TBS-T for $10 \mathrm{~min}$. Membrane washing step was repeated three times. Membranes were incubated with a secondary anti-human Imunoglobulin G (IgG, A0170, Sigma-Aldrich) (1:1000) during $1 \mathrm{~h}$ at room temperature. After washing the membranes, immunodetection was performed with enhanced chemiluminescence ECL (Amersham Pharmacia Biotech) according to the manufacturer's procedure and the images were recorded using X-ray films (GE Healthcare). The films and the gels were scanned in Molecular Imager Gel Doc XR+System (Bio-Rad) and analyzed with QuantityOne software (v. 4.6.9 Bio-Rad).

\subsection{In-gel protein digestion and protein identification by mass spectrometry}

Reactive protein spots were selected and manually excised from stained gels. An in-gel digestion of gel spots, with trypsin TPCK treated (ABSciex), was performed as previously described
(Carvalhais et al., 2015). Briefly, peptides extraction was made with $10 \%$ formic acid/acetonitrile acid. Dried peptides were dissolved in $5 \%$ acetonitrile (VWR), $0.1 \%$ formic acid (Fluka Analytical, Sigma-Aldrich) and 0.1\% trifluoroacetic acid (Sigma-Aldrich). Peptides were directly deposited onto 384-well MALDI plates (Applied Biosystems, Foster City, CA, USA) with $\alpha$-CHCA matrix solution. $\alpha$-CHCA matrix solution was prepared by diluting $2.5 \mathrm{mg} / \mathrm{mL}$ of $\alpha$-CHCA in ACN 70\%/TFA 0.3\%. Experiments were carried out in technical duplicates. Mass spectra were obtained on a matrix assisted laser desorption/ionization-time of flight MALDI-TOF/TOF mass spectrometer (4800 Proteomics Analyzer, Applied Biosystems) in the positive ion reflector mode and obtained in the mass range from 700 to $4500 \mathrm{Da}$ with 900 laser shots. A fragmentation voltage of $2 \mathrm{kV}$ was used throughout the automated runs. The spectra were processed and analyzed by the Global Protein Server (GPS) Workstation (Applied Biosystems). Searches were performed against the SwissProt (release date 06022013 ) protein database for Firmicutes. The database search parameters were: mass tolerance of $40 \mathrm{ppm}$ for precursor ions and 0.4 Da for fragment ions; trypsin digestion with two missed cleavages. Protein identity was accepted at the $95 \%$ confidence level.

\subsection{Bioinformatic analyses}

Gene ontology (GO) (Ashburner et al., 2000) and Kyoto Encyclopedia of Genes and Genomes (KEGG) pathway (Kanehisa et al., 2004) analysis were performed to determine the function of

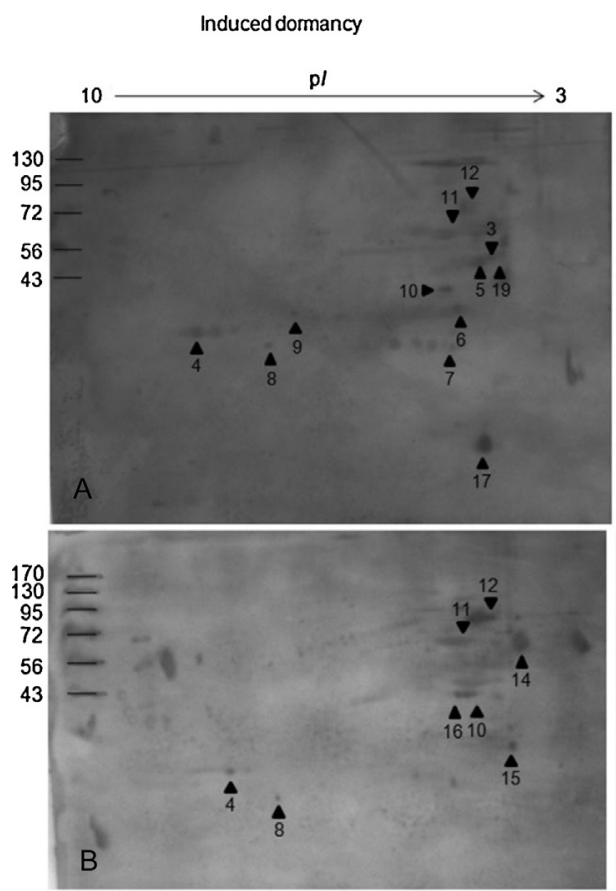

Prevented dormancy
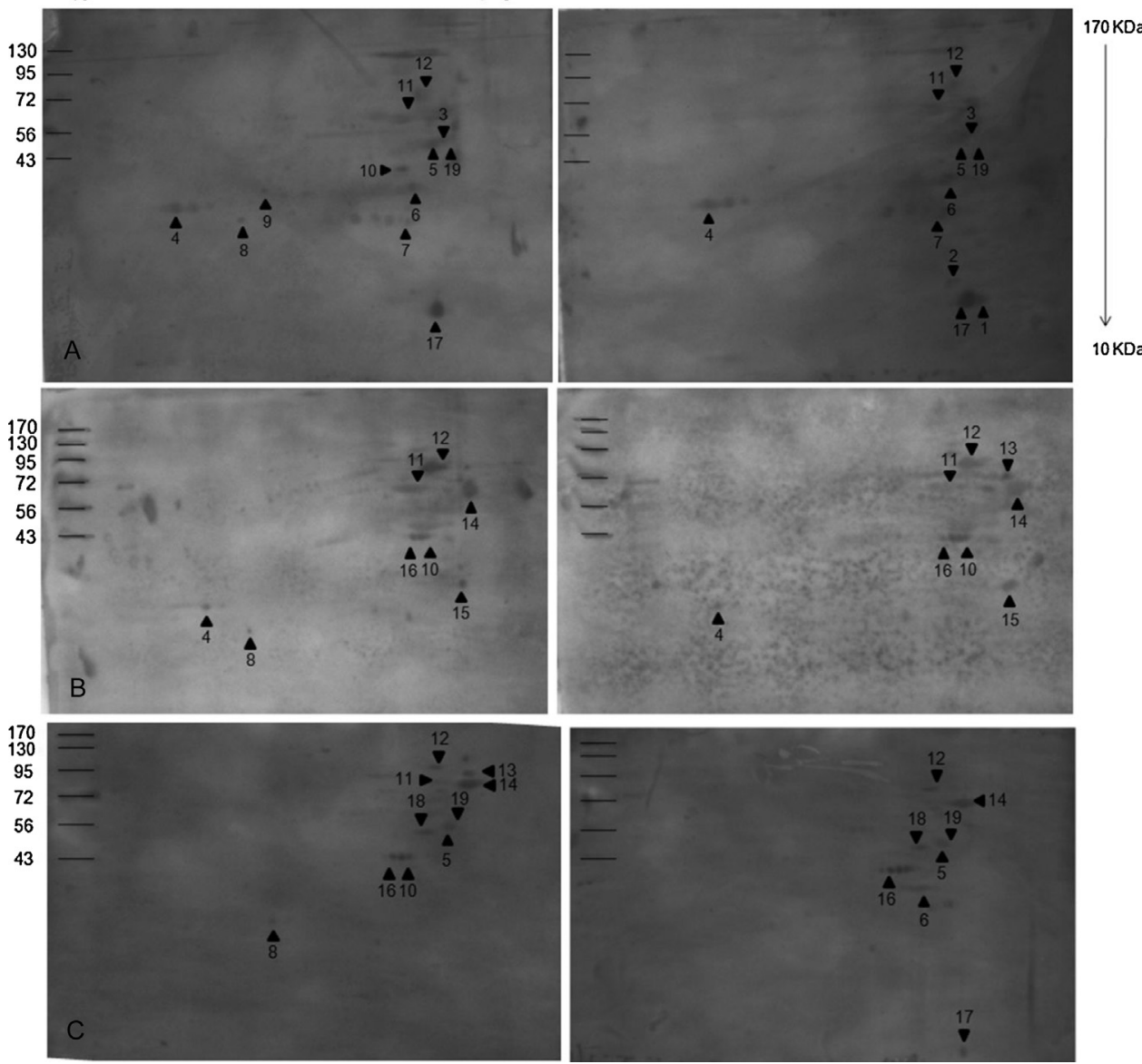

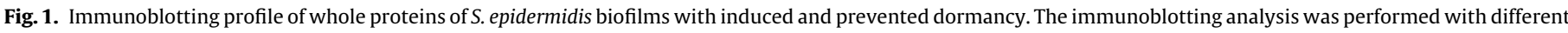
human sera. (A) donor 1, (B) donor 2, and (C) donor 3. Protein spot identification is mentioned in Table 1. 
identified proteins, using the Search Tool for the Retrieval of Interacting Genes/Proteins (STRING) (version 9.1) (at 28112014) (Franceschini et al., 2013). STRING was also used to construct the protein network. Cellular localization of proteins were predicted or identified by PSORTb program v.3.0.2 (Yu et al., 2010) and by Cello v.2.5 (Yu et al., 2004). Immunoreactive proteins were query in ABCPred to predict B cells epitopes in silico (Saha and Raghava, 2006).

\section{Results and discussion}

Biofilm formation is considered the major virulence factor of $S$. epidermidis (Otto, 2009). It has been described that bacteria antigen profile is affected by the mode of bacterial growth (Sanchez et al., 2011), such as planktonic or biofilm cells, which may have potentially meaningful implications in host recognition and consequent immune response. Here, to identify the repertoire of immunoreactive proteins in dormant condition, we characterized the immunoproteome of $S$. epidermidis biofilms with induced and prevented dormancy (see Supplementary Fig. 1), using human serum as a probe. Analysis of the 2-DE separation of whole biofilm cell protein extract from both conditions showed more than 120 protein spots in induced and prevented dormancy (Supplementary Fig. 2). A 2.0 fold-change protein intensity was set as a significant threshold between the two conditions. Apparently, up to 5 spots in each experiment had a fold-change higher than 2.0. The employment of 2-DE methodology in immunoproteomic studies is a powerful tool to identify antigens when combined with Western blotting (Fulton and Twine, 2013). Interestingly, a distinct immunoreactive protein profile of $S$. epidermidis biofilms with prevented and induced dormancy was found in all tested sera (Fig. 1). Our results showed a total of 19 immunoreactive protein spots identified by MALDI-TOF/TOF (Table 1). Most of the immunoreactive proteins spots were located in the $\mathrm{pH}$ range of $4-5$ and in the molecular weight range of $20-40 \mathrm{kDa}$ (Table 1 ).

Only GpmI and FusA proteins were reactive to all tested sera, independently of biofilm dormancy. Both are related to ion binding molecular function, but no more evident connections are known, since GpmI is associated with glycolysis and FusA with protein biosynthesis. On the other hand, GpmA protein seemed to be more immunoreactive in induced dormancy, in all tested sera. Other proteins, such as Pgk, TpiA and Ald, were recognized by only one serum sample. The reactive pattern diversity found among sera samples may be due to differences on immune response of donors or previous exposure to S. epidermidis, since it is a commensal microorganism of skin and mucosae (Otto, 2012). Interestingly, the immunoblot pattern included a set of reactive proteins which seemed to be only immunoreactive in biofilms with induced dormancy, such as CodY and GpmA. Conversely, FtnA and ClpP proteins were reactive in biofilms with prevented dormancy condition. Interestingly, CodY is a GTP-binding protein which responds to GTP and senses nutrient availability, controlling the expression of genes involved in the biosynthesis and transport of amino acids in several Gram-positive species (Sonenshein, 2005). Typically, CodY is repressed during rapid growth and induced when cells experience nutrient deprivation (Sonenshein, 2005), which may be related with dormancy.

Despite no direct involvement with dormancy has been previously described (Amato et al., 2014), genes encoding proteins here identified, have been linked to particular circumstances in biofilms. For example, the expression of $f \operatorname{tn} A$ was affected by the presence of iron and manganese ions in the biofilm growth conditions (Morrissey et al., 2004). Also, the deletion of clpP was associated with a reduced ability to form $S$. epidermidis biofilms and with reduced virulence in a rat model of biofilm-associated infection

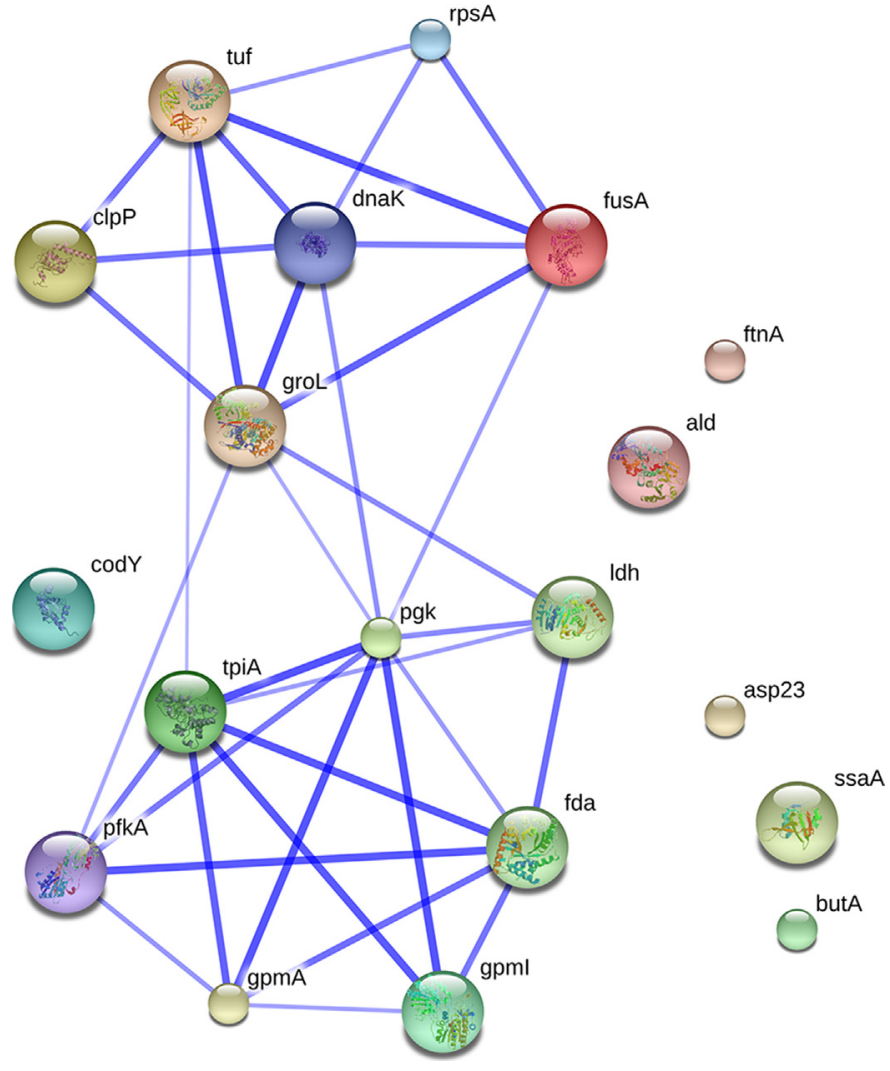

Fig. 2. STRING network generated with immunoreactive proteins identified by 2DEMALDI-TOF/TOF.

(Wang et al., 2007). Interestingly, among the immunoreactive proteins, 3 had previously been reported to be immunoreactive with sera from rabbits infected with live S. epidermidis (Sellman et al., 2005), namely EF-TU, Fda and Ald. Additionally, surface proteins are known to be crucial determinants for host colonization (Scott and Barnett, 2006), such as SsaA, which is a well-known immunogenic protein (Lang et al., 2000). Similarly, in Chlamydia trachomatis, proteins like DnaK, EF-TU, GroEL and RpsA were also immunoreactive (Sanchez-Campillo et al., 1999). Since EF-TU, DnaK and GroEL are highly conserved genes (Craig, 1985), they are frequently found as immunogens in several species (Sanchez-Campillo et al., 1999; Mariappan et al., 2010; Shinoy et al., 2013; Yang et al., 2011). Additionally, EF-TU, DnaK and GroEL are among the proteins here identified, with a higher number of antigenic determinants to Bcell (Van Regenmortel, 2009) (Table 1), which may be the reason for been highly reactive.

In parallel, STRING tool was used to construct the interaction network with immunoreactive proteins. Generated network was enriched in protein interactions as shown in Fig. 2. The three most representative classes of these proteins for biological processes, molecular functions and KEGG pathways are shown in Fig. 3. The immunogenic proteins represented a broad range of biological functions, including small molecule metabolic process (GO:0044281), catabolic processes (GO:0009056), carbohydrate metabolic processes (GO:0005975), generation of precursor metabolites and energy (GO:0006091) and biosynthetic processes (GO: 0009058). These proteins are mainly involved in metabolic pathways, such as glycolysis/gluconeogenesis, microbial metabolism in diverse environments, biosynthesis of secondary metabolites, fructose and mannose metabolism and methane metabolism. The main molecular functions found were related to catalytic activity (GO:0003824), ion binding (GO:0043167) and oxidoreductase activity (GO:0016491). Bioinformatic analyses were 


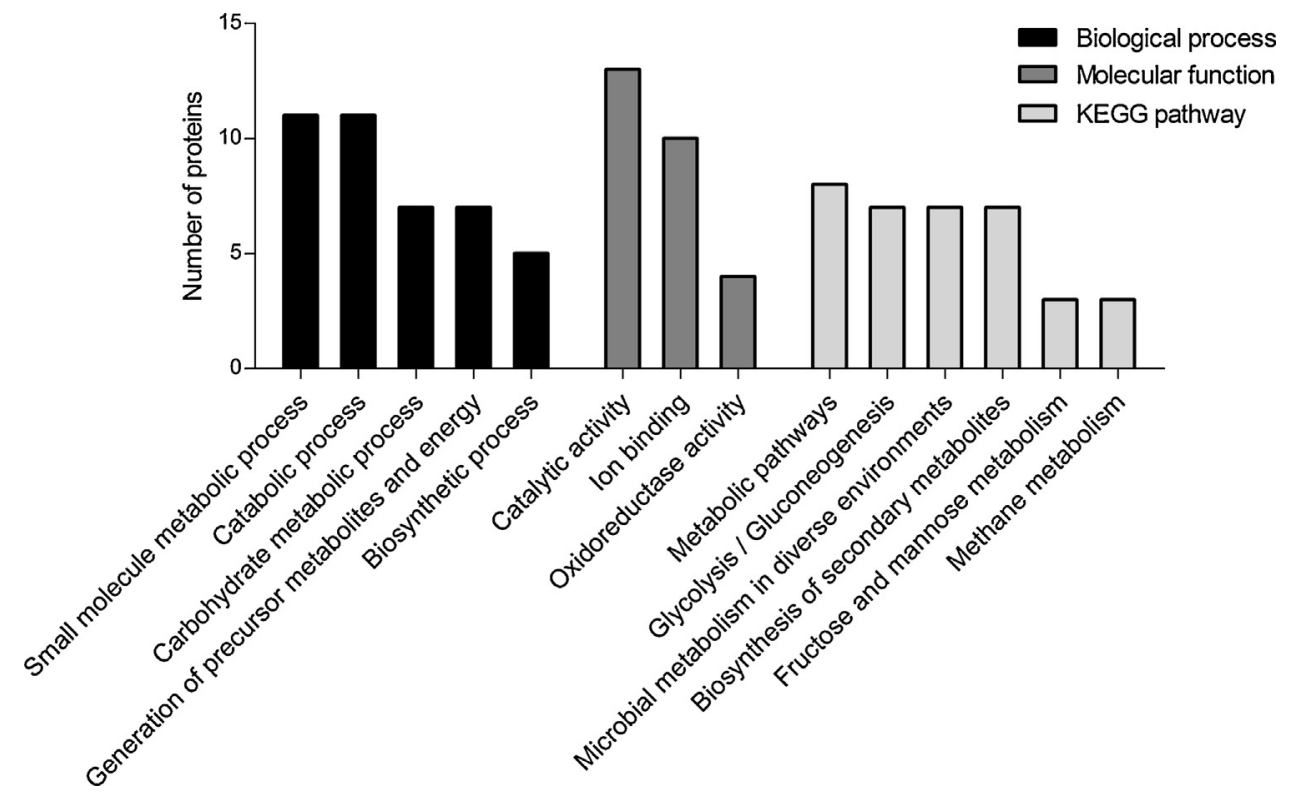

Fig. 3. The most representative GO terms of biological processes, molecular functions and KEGG pathways of immunoreactive proteins.

used to predict subcellular localization of proteins. Results showed one protein with extracellular localization. Remaining proteins were predicted to have cytoplasmic localization (Table 1). These results suggest that ion binding function may influence the host immune response, since previously, we identified this class of proteins with altered expression between $S$. epidermidis biofilms with induced and prevented dormancy (Carvalhais et al., 2015).

\section{Conclusion}

Taken together, our results showed that proteins from S. epidermidis biofilms with prevented and induced dormancy had different reactivity to human serum, providing the first evidences of dormancy impact in the human-bacteria immune interaction. Nevertheless, differences in the reactivity pattern were mainly observed in intracellular proteins, which can present difficult access to immune system. Despite individual host factors, we found differences in the immunoreactive protein pattern between S. epidermidis biofilms with different proportion of dormant bacteria. The immunoreactive proteins made part of a diverse group of proteins, ranging from proteins with proteolysis activity (ClpP), through proteins involved in iron transport (FtnA), proteins associated with glycolysis (GpmA) or proteins with transcription regulation biological function (CodY). In general, it is most likely that immunoreactive proteins are involved in small molecule metabolic processes or catabolic process, with capacity to interact with ion or charged atoms and catalytic activity.

Characterization of dormancy within biofilms using immunoproteomics provided new insights into the protein expression that may determine $S$. epidermidis contact with the host. Moreover, these proteins are promising candidates as biofilm markers allowing the discrimination of physiological condition displayed by biofilm bacteria and will be worth to consider in further studies.

\section{Acknowledgments}

VC had an individual FCT fellowship (SFRH/BD/78235/2011). NC is an Investigator FCT. This work was funded by Fundação para a Ciência e a Tecnologia (FCT) and COMPETE grants PTDC/BIA-MIC/113450/2009, FCOMP-01-0124-FEDER-014309, QOPNA research unit (project PEst-C/QUI/UI0062/2013), RNEM
(National Mass Spetrometry Network) and CENTRO-07-ST24FEDER-002034. The authors also thank the FCT Strategic Project PEst-OE/EQB/LA0023/2013 and the Project "BioHealth - Biotechnology and Bioengineering approaches to improve health quality", Ref. NORTE-07-0124-FEDER-000027, co-funded by the Programa Operacional Regional do Norte (ON.2 - O Novo Norte), QREN, FEDER. The authors also acknowledge the project "Consolidating Research Expertise and Resources on Cellular and Molecular Biotechnology at CEB/IBB”, Ref. FCOMP-01-0124-FEDER-027462.

\section{Appendix A. Supplementary data}

Supplementary data associated with this article can be found, in the online version, at http://dx.doi.org/10.1016/j.molimm. 2015.02.024.

\section{References}

Amato, S.M., Fazen, C.H., Henry, T.C., Mok, W.W., Orman, M.A., Sandvik, E.L., Volzing, K.G., Brynildsen, M.P., 2014. The role of metabolism in bacterial persistence. Front. Microbiol. 5, 70.

Ashburner, M., Ball, C.A., Blake, J.A., Botstein, D., Butler, H., Cherry, J.M., Davis A.P., Dolinski, K., Dwight, S.S., Eppig, J.T., Harris, M.A., Hill, D.P., Issel-Tarver, L., Kasarskis, A., Lewis, S., Matese, J.C., Richardson, J.E., Ringwald, M., Rubin, G.M. Sherlock, G., 2000. Gene ontology: tool for the unification of biology. The Gene Ontology Consortium. Nat. Genet. 25, 25-29.

Brady, R.A., Leid, J.G., Camper, A.K., Costerton, J.W., Shirtliff, M.E., 2006. Identification of Staphylococcus aureus proteins recognized by the antibody-mediated immune response to a biofilm infection. Infect. Immun. 74, 3415-3426.

Carvalhais, V., Cerca, N., Vilanova, M., Vitorino, R., 2015. Proteomic profile of dormancy within Staphylococcus epidermidis biofilms using iTRAQ and label-free strategies. Appl. Microbiol. Biotechnol. 99, 2751-2762.

Carvalhais, V., Franca, A., Cerca, F., Vitorino, R., Pier, G.B., Vilanova, M., Cerca, N., 2014 Dormancy within Staphylococcus epidermidis biofilms: a transcriptomic analysis by RNA-seq. Appl. Microbiol. Biotechnol. 98, 2585-2596.

Carvalhais, V., Franca, A., Pier, G.B., Vilanova, M., Cerca, N., Vitorino, R., 2015. Comparative proteomic and transcriptomic profile of Staphylococcus epidermidis biofilms grown in glucose-enriched medium. Talanta 132, 705-712.

Cerca, F., Andrade, F., Franca, A., Andrade, E.B., Ribeiro, A., Almeida, A.A., Cerca, N. Pier, G., Azeredo, J., Vilanova, M., 2011. Staphylococcus epidermidis biofilms with higher proportions of dormant bacteria induce a lower activation of murine macrophages. J. Med. Microbiol. 60, 1717-1724.

Cerca, F., Franca, A., Perez-Cabezas, B., Carvalhais, V., Ribeiro, A., Azeredo, J., Pier G.B., Cerca, N., Vilanova, M., 2014. Dormant bacteria within Staphylococcus epidermidis biofilms have low inflammatory properties and maintain tolerance to vancomycin and penicillin after entering planktonic growth. J. Med. Microbiol. 63, 1274-1283. 
Cerca, N., Jefferson, K.K., Oliveira, R., Pier, G.B., Azeredo, J., 2006. Comparative antibody-mediated phagocytosis of Staphylococcus epidermidis cells grown in a biofilm or in the planktonic state. Infect. Immun. 74, 4849-4855.

Cerca, N., Martins, S., Cerca, F., Jefferson, K.K., Pier, G.B., Oliveira, R., Azeredo, J., 2005. Comparative assessment of antibiotic susceptibility of coagulasenegative staphylococci in biofilm versus planktonic culture as assessed by bacterial enumeration or rapid XTT colorimetry. J. Antimicrob. Chemother. 56, $331-336$

Cheung, G.Y., Rigby, K., Wang, R., Queck, S.Y., Braughton, K.R., Whitney, A.R., Teintze M., DeLeo, F.R., Otto, M., 2010. Staphylococcus epidermidis strategies to avoid killing by human neutrophils. PLoS. Pathog. 6.

Costa, R.M., Nogueira, F., de Sousa, K.P., Vitorino, R., Silva, M.S., 2013. Immunoproteomic analysis of Plasmodium falciparum antigens using sera from patients with clinical history of imported malaria. Malar. J. 12, 100.

Costerton, J.W., Stewart, P.S., Greenberg, E.P., 1999. Bacterial biofilms: a common cause of persistent infections. Science 284, 1318-1322.

Craig, E.A., 1985. The heat shock response. CRC Crit. Rev. Biochem. 18, 239-280.

Dennehy, R., McClean, S., 2012. Immunoproteomics: the key to discovery of new vaccine antigens against bacterial respiratory infections. Curr. Protein Pept. Sci. 13, 807-815

Franca, A., Carvalhais, V., Maira-Litran, T., Vilanova, M., Cerca, N., Pier, G., 2014. Alterations in the Staphylococcus epidermidis biofilm transcriptome following interaction with whole human blood. Pathog. Dis. 70, 444-448.

Franceschini, A., Szklarczyk, D., Frankild, S., Kuhn, M., Simonovic, M., Roth, A Lin, J., Minguez, P., Bork, P., von Mering, C., Jensen, L.J., 2013. STRING v9.1: protein-protein interaction networks, with increased coverage and integration. Nucleic Acids Res. 41, D808-D815.

Fulton, K.M., Twine, S.M., 2013. Immunoproteomics: current technology and applications. Methods Mol. Biol. 1061, 21-57.

Gray, E.D., Peters, G., Verstegen, M., Regelmann, W.E., 1984. Effect of extracellular slime substance from Staphylococcus epidermidis on the human cellular immune response. Lancet $1,365-367$

Hanke, M.L., Kielian, T., 2012. Deciphering mechanisms of staphylococcal biofilm evasion of host immunity. Front. Cell. Infect. Microbiol. 2, 62.

Jesaitis, A.J., Franklin, M.J., Berglund, D., Sasaki, M., Lord, C.I., Bleazard, J.B., Duffy, J.E. Beyenal, H., Lewandowski, Z., 2003. Compromised host defense on Pseudomonas aeruginosa biofilms: characterization of neutrophil and biofilm interactions. J. Immunol. 171, 4329-4339.

Johnson, G.M., Lee, D.A., Regelmann, W.E., Gray, E.D., Peters, G., Quie, P.G., 1986. Interference with granulocyte function by Staphylococcus epidermidis slime. Infect. Immun. 54, 13-20

Kanehisa, M., Goto, S., Kawashima, S., Okuno, Y., Hattori, M., 2004. The KEGG resource for deciphering the genome. Nucleic Acids Res. 32, D277-D280.

Kaprelyants, A.S., Gottschal, J.C., Kell, D.B., 1993. Dormancy in non-sporulating bacteria. FEMS Microbiol. Rev. 10, 271-285

Kim, J., Hahn, J.S., Franklin, M.J., Stewart, P.S., Yoon, J., 2009. Tolerance of dormant and active cells in Pseudomonas aeruginosa PA01 biofilm to antimicrobial agents. J. Antimicrob. Chemother. 63, 129-135.

Kristian, S.A., Birkenstock, T.A., Sauder, U., Mack, D., Gotz, F., Landmann, R., 2008. Biofilm formation induces C3a release and protects Staphylococcus epidermidis from IgG and complement deposition and from neutrophil-dependent killing. J. Infect. Dis. 197, 1028-1035.

Lang, S., Livesley, M.A., Lambert, P.A., Littler, W.A., Elliott, T.S., 2000. Identification of a novel antigen from Staphylococcus epidermidis. FEMS Immunol. Med. Microbiol. 29, 213-220

Leid, J.G., Shirtliff, M.E., Costerton, J.W., Stoodley, P., 2002. Human leukocytes adhere to, penetrate, and respond to Staphylococcus aureus biofilms. Infect. Immun. 70 6339-6345.

Lewis, K., 2007. Persister cells, dormancy and infectious disease. Nat. Rev. Microbiol. $5,48-56$

Mack, D., Siemssen, N., Laufs, R., 1992. Parallel induction by glucose of adherence and a polysaccharide antigen specific for plastic-adherent Staphylococcus epider midis: evidence for functional relation to intercellular adhesion. Infect. Immun. $60,2048-2057$

Mariappan, V., Vellasamy, K.M., Thimma, J.S., Hashim, O.H., Vadivelu, J., 2010. Identification of immunogenic proteins from Burkholderia cepacia secretome using proteomic analysis. Vaccine 28, 1318-1324.

Morrissey, J.A., Cockayne, A., Brummell, K., Williams, P., 2004. The staphylococca ferritins are differentially regulated in response to iron and manganese and via PerR and Fur. Infect. Immun. 72, 972-979.

Otto, M., 2009. Staphylococcus epidermidis - the 'accidental' pathogen. Nat. Rev. Microbiol. 7, 555-567.

Otto, M., 2012. Molecular basis of Staphylococcus epidermidis infections. Semin. Immunopathol. 34, 201-214.
Otto, M., 2014. Staphylococcus epidermidis pathogenesis. Methods Mol. Biol. 1106, $17-31$

Pourmand, M.R., Clarke, S.R., Schuman, R.F., Mond, J.J., Foster, S.J., 2006. Identification of antigenic components of Staphylococcus epidermidis expressed during human infection. Infect. Immun. 74, 4644-4654

Rani, S.A., Pitts, B., Beyenal, H., Veluchamy, R.A., Lewandowski, Z., Davison, W.M. Buckingham-Meyer, K., Stewart, P.S., 2007. Spatial patterns of DNA replication, protein synthesis, and oxygen concentration within bacterial biofilms reveal diverse physiological states. J. Bacteriol. 189, 4223-4233.

Rupp, M.E., Ulphani, J.S., Fey, P.D., Mack, D., 1999. Characterization of Staphylococcus epidermidis polysaccharide intercellular adhesin/hemagglutinin in the pathogenesis of intravascular catheter-associated infection in a rat model. Infect. Immun. 67, 2656-2659.

Saha, S., Raghava, G.P., 2006. Prediction of continuous B-cell epitopes in an antigen using recurrent neural network. Proteins 65, 40-48.

Sanchez, C.J., Hurtgen, B.J., Lizcano, A., Shivshankar, P., Cole, G.T., Orihuela, C.J., 2011 Biofilm and planktonic pneumococci demonstrate disparate immunoreactivity to human convalescent sera. BMC Microbiol. 11, 245.

Sanchez-Campillo, M., Bini, L., Comanducci, M., Raggiaschi, R., Marzocchi, B., Pallini, V., Ratti, G., 1999. Identification of immunoreactive proteins of Chlamydia trachomatis by Western blot analysis of a two-dimensional electrophoresis map with patient sera. Electrophoresis 20, 2269-2279.

Scherr, T.D., Heim, C.E., Morrison, J.M., Kielian, T., 2014. Hiding in plain sight: interplay between staphylococcal biofilms and host immunity. Front. Immunol. 5 37.

Schuster, S., Yu, W., Nega, M., Chu, Y.Y., Zorn, S., Zhang, F., Gotz, F., Schreiber, F., 2014. The role of serum proteins in Staphylococcus aureus adhesion to ethylene glycol coated surfaces. Int. J. Med. Microbiol. 304, 949-957.

Scott, J.R., Barnett, T.C., 2006. Surface proteins of Gram-positive bacteria and how they get there. Annu. Rev. Microbiol. 60, 397-423.

Sellman, B.R., Howell, A.P., Kelly-Boyd, C., Baker, S.M., 2005. Identification of immunogenic and serum binding proteins of Staphylococcus epidermidis. Infect. Immun. 73, 6591-6600

Shapiro, J.A., Nguyen, V.L., Chamberlain, N.R., 2011. Evidence for persisters in Staphylococcus epidermidis RP62a planktonic cultures and biofilms. J. Med. Microbiol. 60, 950-960.

Shinoy, M., Dennehy, R., Coleman, L., Carberry, S., Schaffer, K., Callaghan, M., Doyle S., McClean, S., 2013. Immunoproteomic analysis of proteins expressed by two related pathogens, Burkholderia multivorans and Burkholderia cenocepacia, during human infection. PLoS ONE 8, e80796.

Sonenshein, A.L., 2005. CodY, a global regulator of stationary phase and virulence in Gram-positive bacteria. Curr. Opin. Microbiol. 8, 203-207.

Van Regenmortel, M.H., 2009. What is a B-cell epitope? Methods Mol. Biol. 524 $3-20$

Vuong, C., Voyich, J.M., Fischer, E.R., Braughton, K.R., Whitney, A.R., DeLeo, F.R., Otto M., 2004. Polysaccharide intercellular adhesin (PIA) protects Staphylococcus epidermidis against major components of the human innate immune system. Cell Microbiol. 6, 269-275.

Wang, C., Li, M., Dong, D., Wang, J., Ren, J., Otto, M., Gao, Q., 2007. Role of ClpP in biofilm formation and virulence of Staphylococcus epidermidis. Microbes Infect. 9, 1376-1383.

Wang, J., Du, X.J., Lu, X.N., Wang, S., 2013. Immunoproteomic identification o immunogenic proteins in Cronobacter sakazakii strain BAA-894. Appl. Microbiol. Biotechnol. 97, 2077-2091.

Williamson, K.S., Richards, L.A., Perez-Osorio, A.C., Pitts, B., McInnerney, K., Stewart, P.S., Franklin, M.J., 2012. Heterogeneity in Pseudomonas aeruginosa biofilms includes expression of ribosome hibernation factors in the antibiotic-tolerant subpopulation and hypoxia-induced stress response in the metabolically active population. J. Bacteriol. 194, 2062-2073.

Yang, Y., Wang, L., Yin, J., Wang, X., Cheng, S., Lang, X., Wang, X., Qu, H., Sun, C. Wang, J., Zhang, R., 2011. Immunoproteomic analysis of Brucella melitensis and identification of a new immunogenic candidate protein for the development of brucellosis subunit vaccine. Mol. Immunol. 49, 175-184.

Yao, Y., Sturdevant, D.E., Otto, M., 2005. Genomewide analysis of gene expression in Staphylococcus epidermidis biofilms: insights into the pathophysiology of S epidermidis biofilms and the role of phenol-soluble modulins in formation of biofilms. J. Infect. Dis. 191, 289-298.

Yu, C.S., Lin, C.J., Hwang, J.K., 2004. Predicting subcellular localization of proteins for Gram-negative bacteria by support vector machines based on n-peptide compositions. Protein Sci. 13, 1402-1406.

Yu, N.Y., Wagner, J.R., Laird, M.R., Melli, G., Rey, S., Lo, R., Dao, P., Sahinalp, S.C., Ester M., Foster, L.J., Brinkman, F.S., 2010. PSORTb 3.0: improved protein subcellular localization prediction with refined localization subcategories and predictive capabilities for all prokaryotes. Bioinformatics 26, 1608-1615. 